\title{
Geophysical studies applied to near-surface karst structures: the dolines
}

\author{
Emanuele Bozzo, Silvia Lombardo and Fulvio Merlanti \\ Dipartimento di Scienze della Terra, Università di Genova, Italy
}

\begin{abstract}
The formation of dolines is a very common near-surface karst phenomenon which is widespread and evident throughout most of Italy. In this study different geophysical methods have been applied to doline-like structures in the volcaniclastic section of the Alps in order to define their main morpho-structural characteristics. An integrated analysis of the geophysical data was also carried out to ascertain the quality and the resolution obtained through these geophysical methods and more in general, to evaluate their applicability to areas displaying features which are similar to those currently investigated. The fundamental differences found in different dolines are related to the geometries of the contact between the sublayer and the infill and to the mineralogy of the latter. From a geophysical standpoint the contact represents a discontinuity between materials characterized by different geophysical properties, whereas the infill shows properties which vary according to their
composition and texture.
\end{abstract}

Key words applied geophysics - karst structures dolines - shallow prospection

\section{Introduction}

The most important features of the dolines show a broad spectrum of variability controlled by the predominant type of morphogenic process (i.e. dissolution, erosion, gravity) and by lithological, structural and climatic factors which influence their evolution.

According to the influence of these elements on the entire process of formation, different types of dolines have been recognized. Conventionally, in the literature (Milanovic,
1981; Castiglioni, 1986) dolines are classified according to their shape (e.g., cup-, dish-, funnel-, well-shaped dolines) or their origin (normal dissolution, alluvial, subsidence in rocks, collapse dolines). In general all these types of dolines differ from each other essentially for the characteristics of the rock sublayer and the geometries (thicknesses) and composition of their subsequent cover and infill. After all, these characteristics can be well described by the morphology and geometry of the contact between the sublayer and the infill, which, from a geophysical point of view, forms a discontinuity between materials with different physical properties. For these reasons, this contact is the focus of the geophysical study as it was planned in this work. 


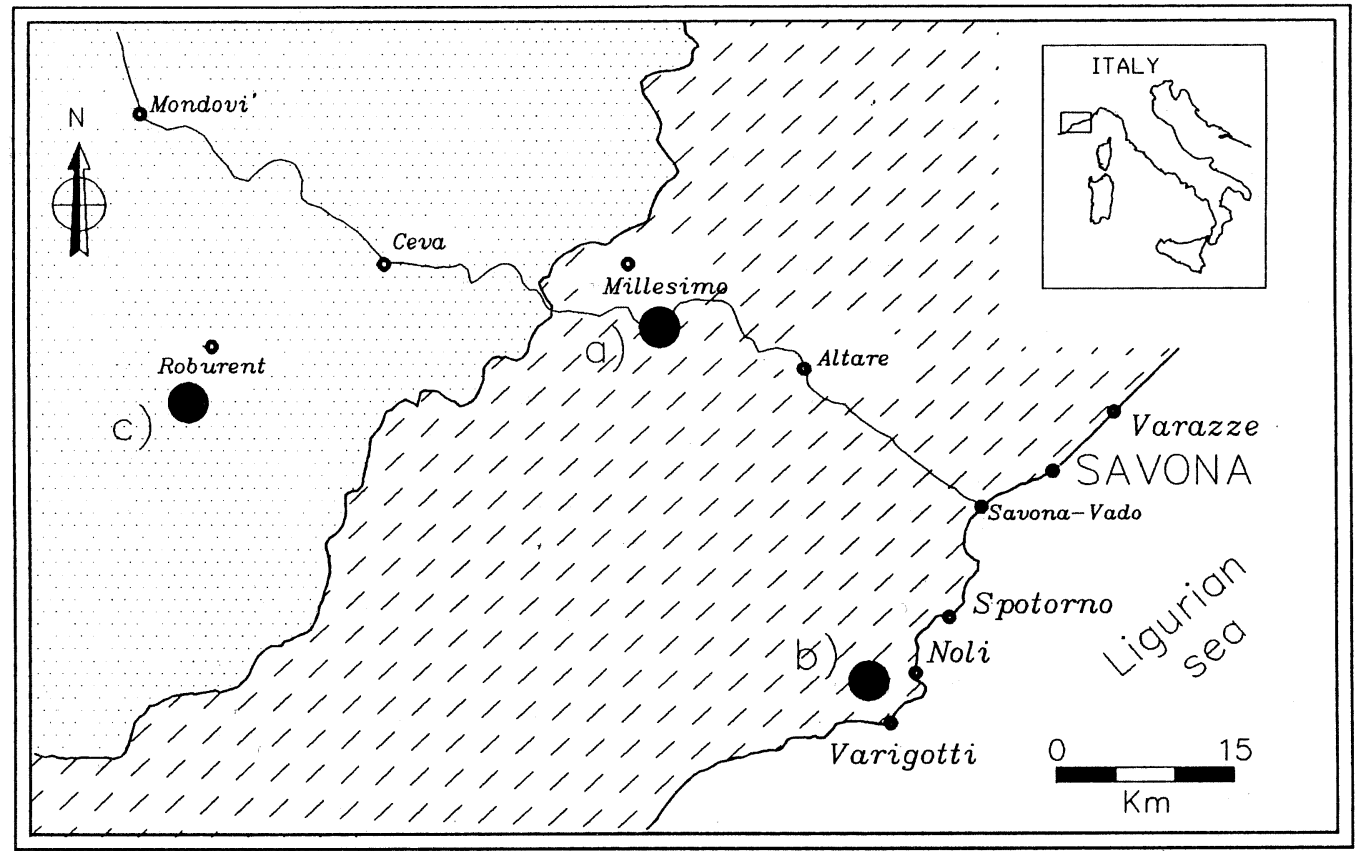

Fig. 1. Location of the dolines investigated with geophysical methods. a) Bric Tana site (SV); b) the Caves site $(\mathrm{SV})$; c) Turbiglie Basin site $(\mathrm{CN})$.

Four examples of dolines, which belong to three karst areas of different types (fig. 1), were selected for the experimental applications of this study: the karst area of the Bric Tana located SE of Millesimo (Savona) and that of the Manie Plateau (Savona), both of them located on the Tyrrhenian side of the Ligurian Alps, and the karst area of Roburent (Cuneo) located on the Po valley side of the Ligurian Alps.

\section{Case 1: Bric Tana (Millesimo - Savona)}

The geophysical investigations were carried out using four different methods, i.e. the VLF (Very Low Frequency) electromagnetic method, the magnetic method (profiles and maps of total magnetic field and magnetic susceptibility measurements), the geoelectric method (profiles, vertical electrical soundings and maps of apparent resistivity) and the shallow refraction seismic method.

The karst features present in the Bric Tana area are of the near-surface type and consisted of a series of doline-shaped depressions of limited sizes with SE-NW elongation. The area, which lies on formations belonging to the Tertiary Basin of Piedmont (Northwestern Italy) and, in particular, to the marly sandstone complex of the Molare Formation (Cortemiglia et al., 1968) is affected by an evident pseudokarst event. The occurrence of coral-bearing limestone lenses intercalated within the sandstone complex and the existence of sub-vertical fracture planes common to both formations, besides a past meteoric regime much more abundant than the present one, provides elements which can explain the peculiar karst genesis of this area. Geophysical investigations have been carried out on two of these dolines, which are hereunder referred to as Dolines 1 and 2. 


\subsection{Doline 1}

Doline 1 belongs to the cup-shaped type with irregular margins and shows a maximum elongation of about $200 \mathrm{~m}$ along the SE-NW direction (fig. 2). The bottom of the doline is covered by a thick colluvial overburden with abundant vegetation and also has three small shallowers. Figure 2 shows the location of the lines of the geophysical survey.

The VLF profiles related to the first three lines of the survey (fig. 3) indicate that:

i) the relative values of the intensity of the in-quadrature component are always higher than those of the in-phase, an event which frequently occurs when a conductive overburden is present; ii) the phase/quadrature ratio varies more in the central parts of the doline than at its margins, thus producing bands of maximum conductivity contrast. This contrast was initially correlated with changes in thickness of the conductive overburden.

In order to verify this interpretation a series of resistivity profiles with the Wenner array and different spacings, were carried out relatively to line $1 \mathrm{~A}$, where the strongest anomaly occurs, so that the pseudosection of apparent resistivity could be constructed. This pseudosection (fig. 4) highlights how the margins of the VLF anomaly closely correspond to those zones where the contact between sublayer and infill displays the steepest inclination, thus delineating the areas with the maximum thick-

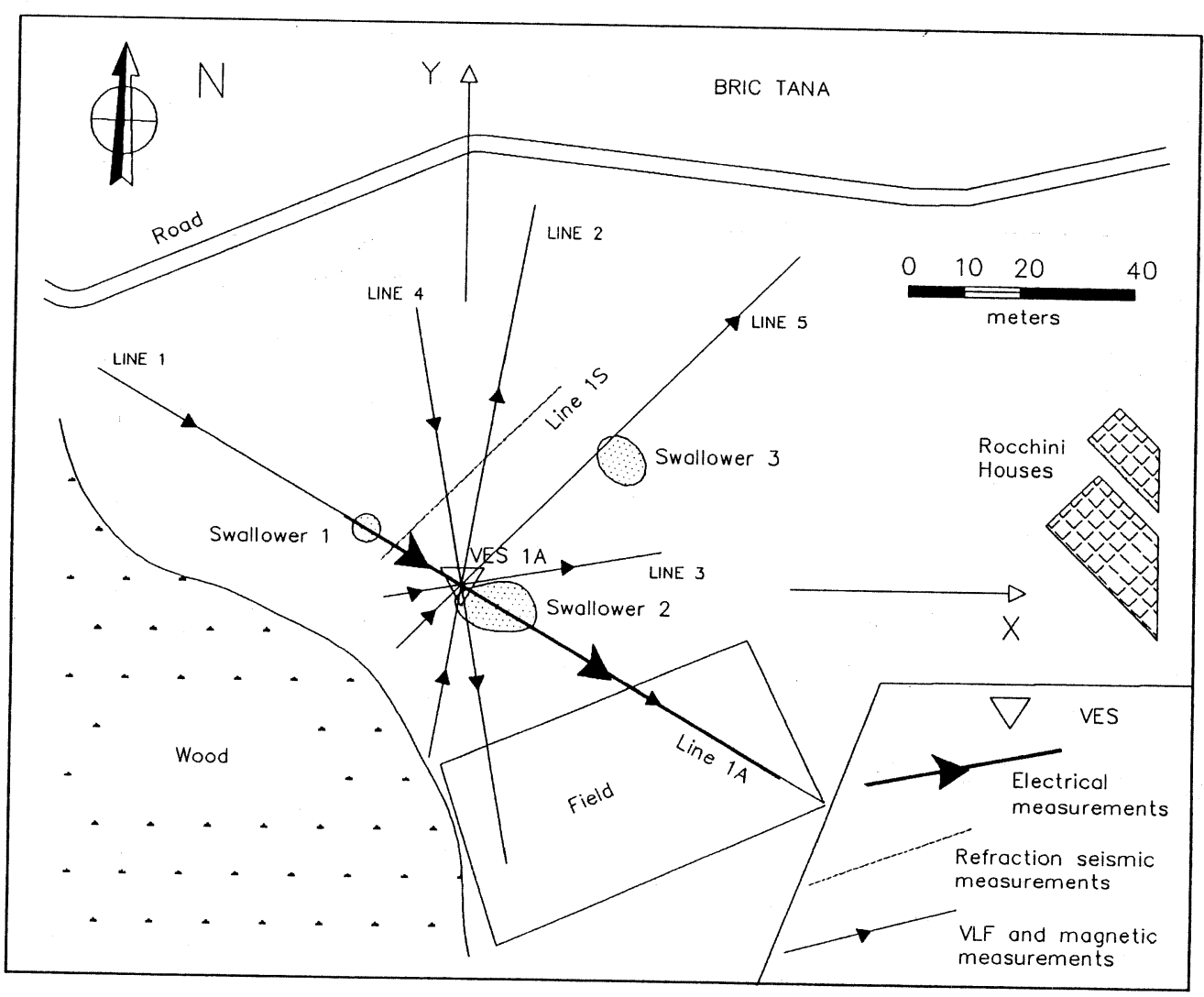

Fig. 2. Bric Tana site. Doline 1: schematic plan of the area and position of the survey lines. 

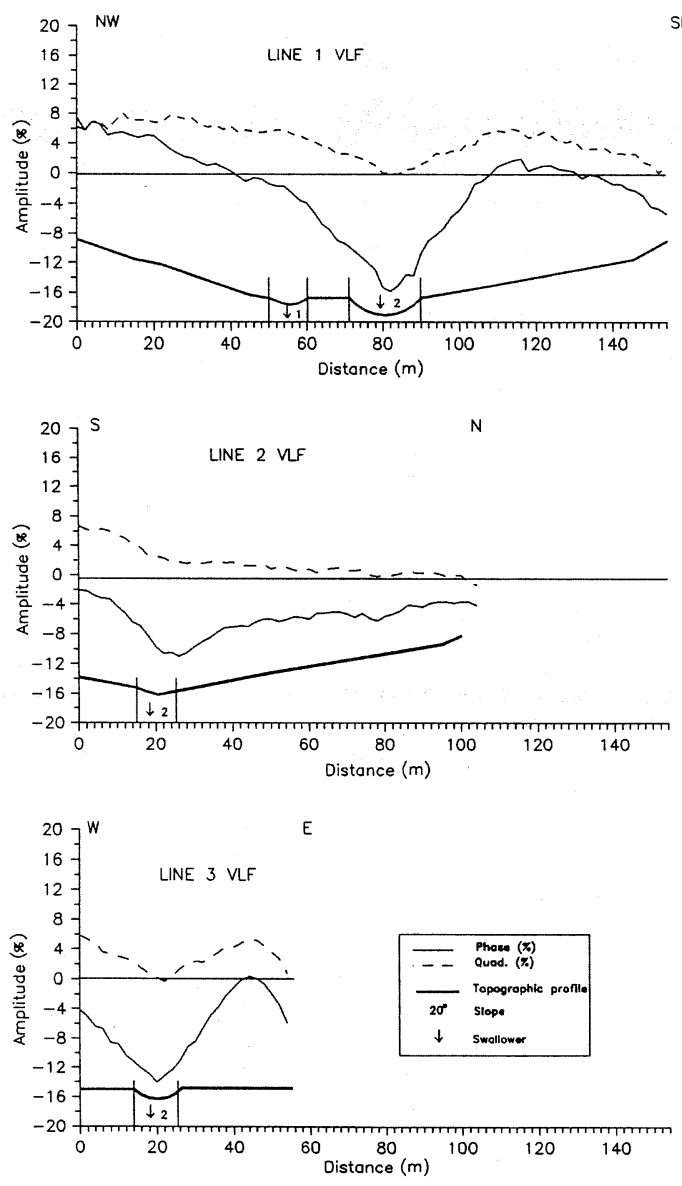

Fig. 3. Bric Tana site. Doline 1: VLF profiles for the survey lines $1,2,3$ of fig. 2 .
SE ness of the overburden. If this interpretation is extrapolated to the entire doline it is possible, on the VLF map of fig. 5, to recognize the areas with maximum thickness of the overburden corresponding to minima of the in-phase component; this correlation has only local significance because the sign of the VLF components depends on the geometry of the survey and the azimuth of the transmitter (Bozzo et al., 1994).

From the map of the total magnetic anomaly (fig. 6), obtained from the residuation of the observed field by subtracting the local reference field of $46.000 \mathrm{nT}$, a surprising similarity between the shapes of the magnetic and VLF anomalies can be observed. A high is located at the centre of the doline and is elongate along the SE-NW direction indicating that the contrast between sublayer and overburden previously defined is also characterized by a magnetization contrast. Along this direction a seismic refraction profile was carried out. The seismic stratigraphy obtained from this survey (fig. 7a,b) shows a progressive deepening of the refractor towards the NE: it has been identified as the contact between the sublayer and the infill inferring a possible thickness of the overburden ranging between about 2 to $4 \mathrm{~m}$. This thickness satisfactorily agrees with that of about $5 \mathrm{~m}$ derived from the Vertical Electrical Sounding (VES) at the centre of the doline.

Ground evidence integrated with some VLF and magnetic features suggests that the cupshape of the doline is due to phenomena of normal dissolution and is not controlled by major fracturing.

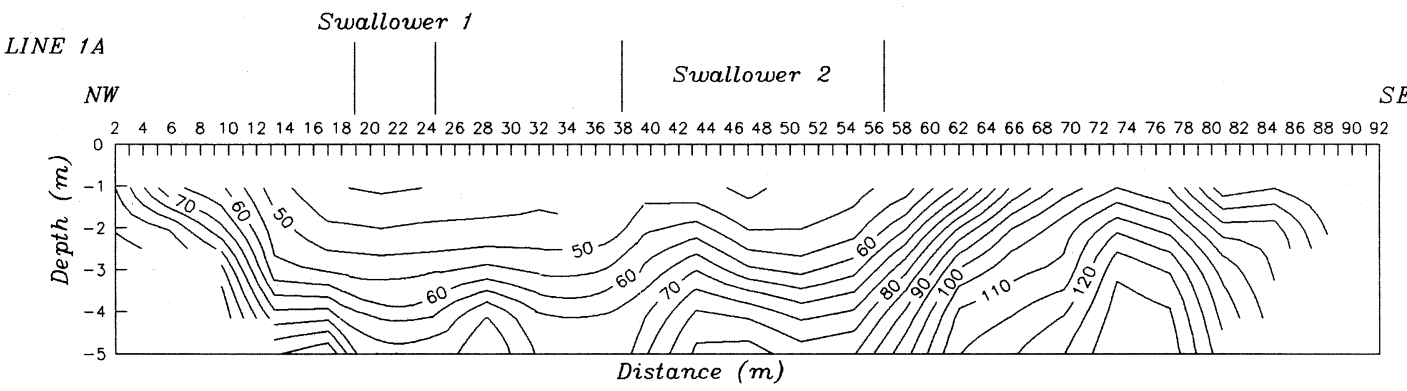

Fig. 4. Bric Tana site. Doline 1: pseudosection of apparent resistivity along line 1A of fig. 2. 


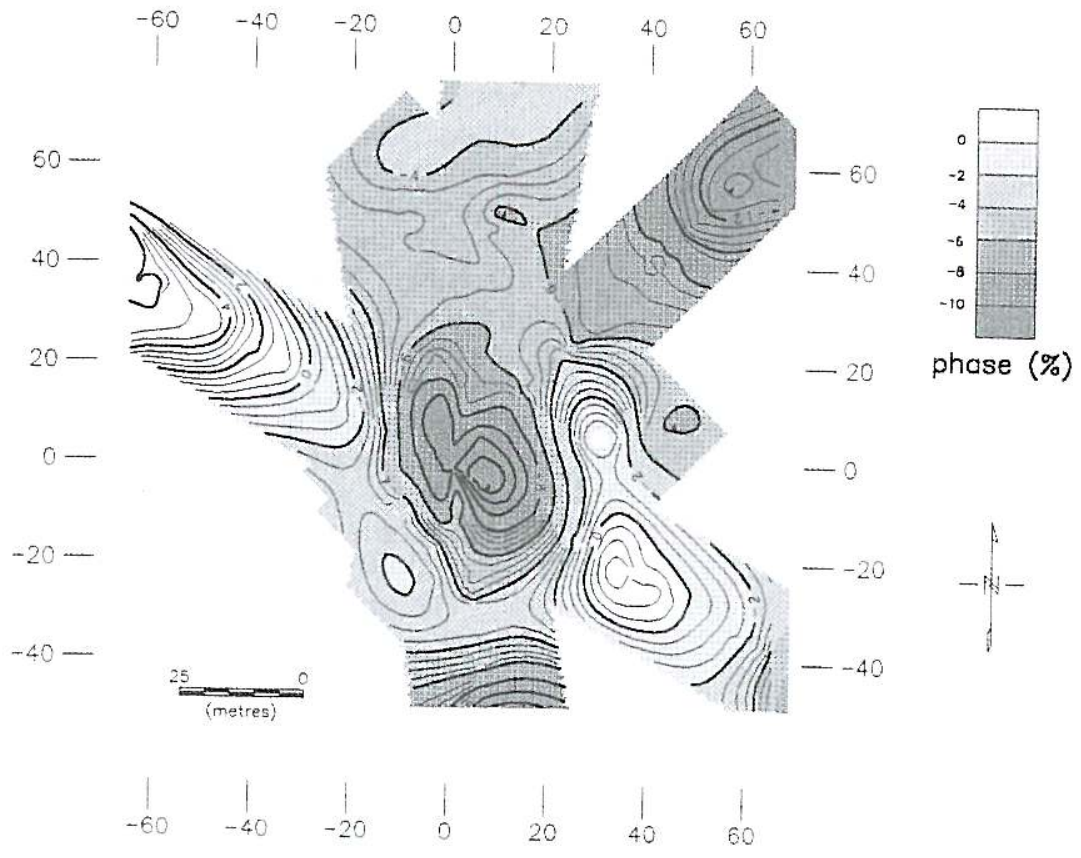

Fig. 5. Bric Tana site. Doline 1: map of the VLF (\%) in-phase component.

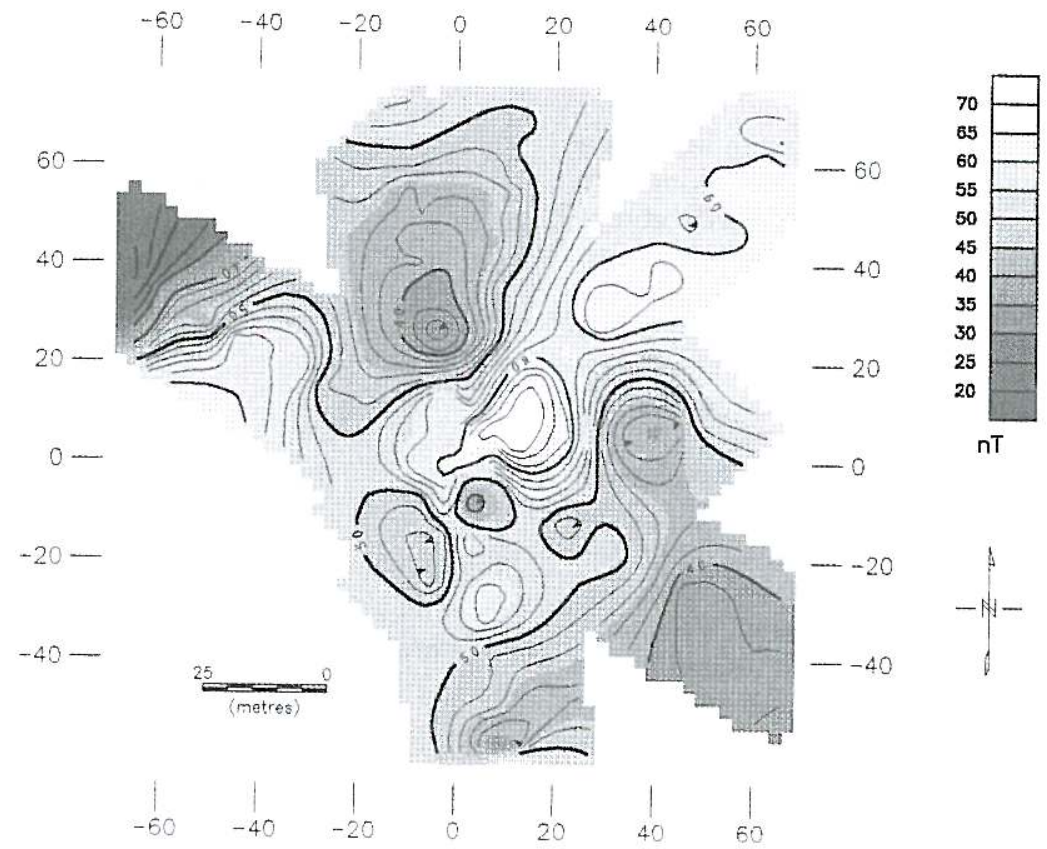

Fig. 6. Bric Tana site. Doline 1: map of the total magnetic anomaly field $\Delta F(\mathrm{nT})$. 

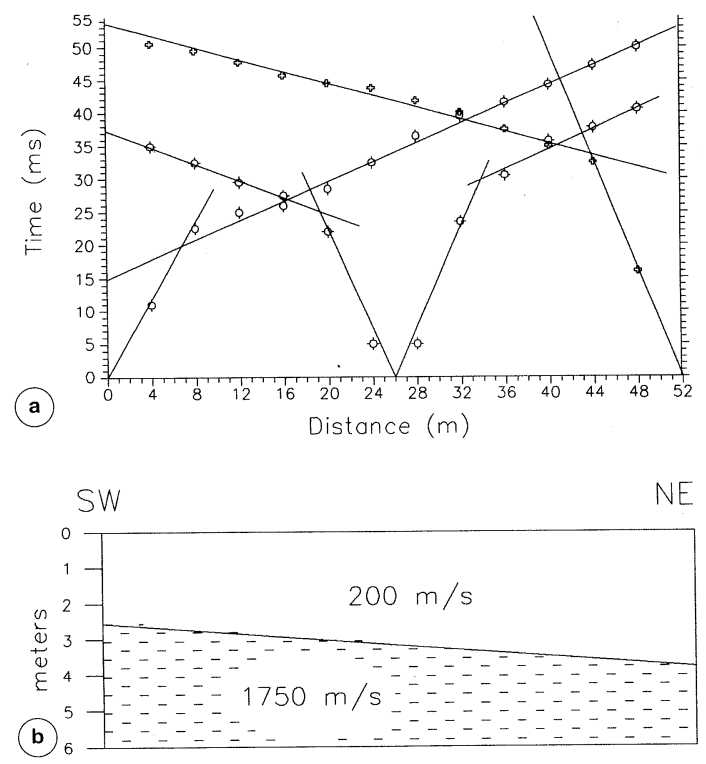

Fig. 7a,b. Bric Tana site. Doline 1: seismic refraction profile along line $1 \mathrm{~S}$ of fig. 2. a) Dromocrones; b) seismic stratigraphy.

\subsection{Doline 2}

This doline displays a flat bottom and has a pseudorectangular shape elongate along the SE-NW direction (fig. 8). An SW-NE abrupt escarpment along the slope divides it into two sections with the western part lower than the eastern one and probably formed during a late stage of the evolution of the doline. The investigations were carried out in the eastern sector along the four lines of fig. 8 .

From the map of the in-phase VLF component (fig. 9) it can be observed that the highest values (high conductivity values) closely follow the outer borders of the doline. This hypothesis is confirmed by the analysis of the apparent resistivity pseudosections related to the four lines of measurement. These pseudosections (fig. 10) highlight the existence of a transition between the two different resistivity media (sublayer and overburden), which is subhorizontal and interrupted by steeply dipping surfaces. These surfaces probably represent the evidence of those fracture planes along which the collapse of the sublayer forming the different stages of the evolution of the doline took place. These collapse phenomena may have been caused by the dissolution of more soluble and deeper rocks, which were not recognized through the geophysical prospection and are probably represented by the coral-bearing limestone previously reported. Furthermore the overburden reaches maximum thickness in the northwestern area.

In the NW section of profile 3 the sublayeroverburden transition is located deeper than the maximum depth of the electrical sections. A refraction line was carried out along that line (fig. 11a,b).

The seismic stratigraphy highlights that the refractor coinciding with the sublayer-overbur-

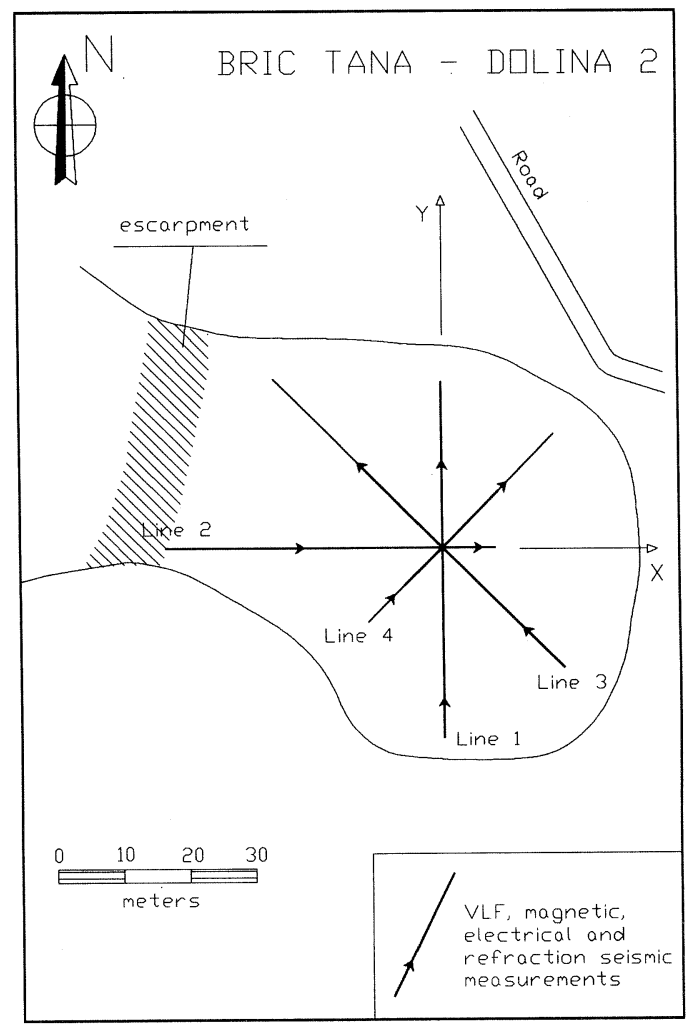

Fig. 8. Bric Tana site. Doline 2: schematic plan of the investigated area and position of the survey lines. 


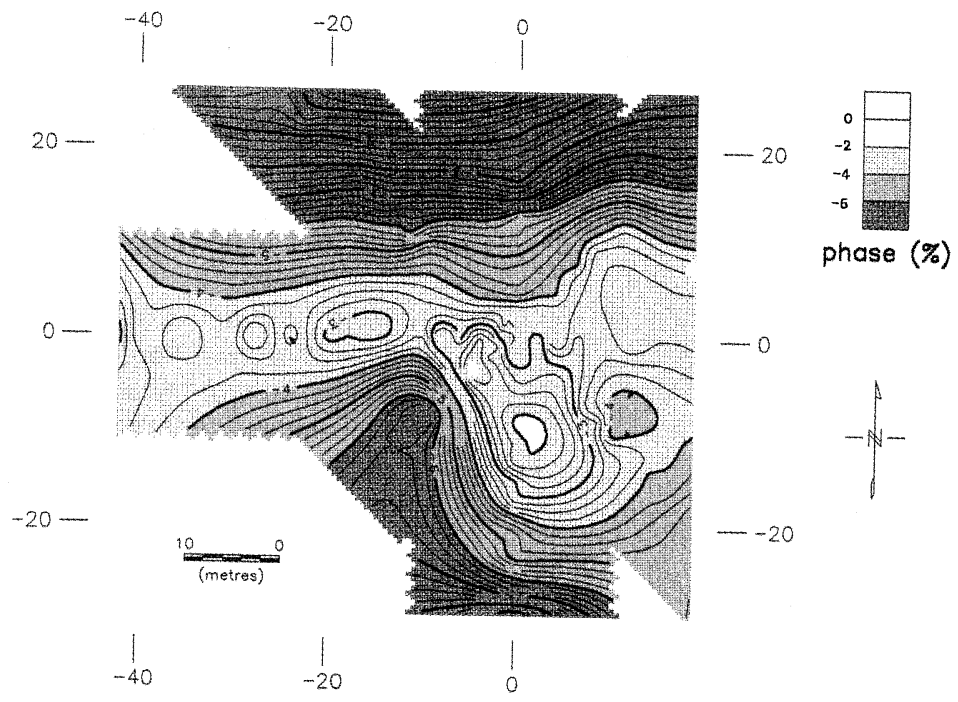

Fig. 9. Bric Tana site. Doline 2: map of the VLF (\%) in-phase component.
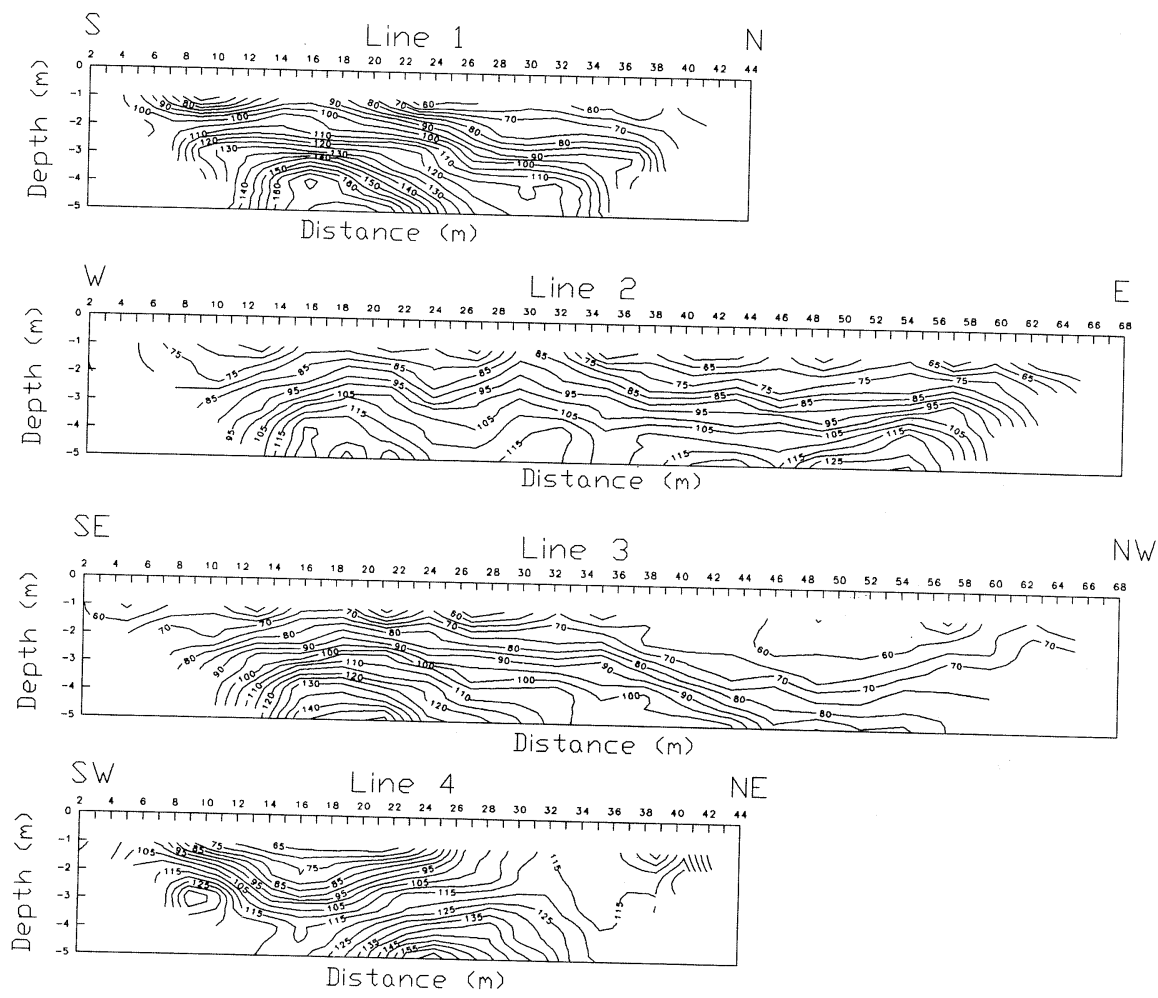

Fig. 10. Bric Tana site. Doline 2: pseudosections of apparent resistivity for the survey lines 1, 2, 3, 4 of
fig. 8 . 

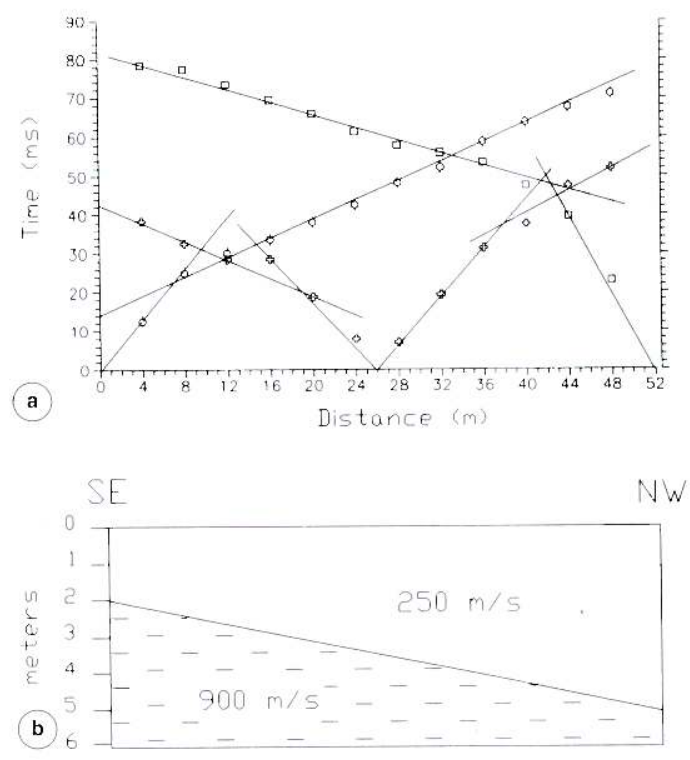

Fig. 11a,b. Bric Tana site. Doline 2: seismic refraction profile along line 3 of fig. 8. a) Dromocrones; b) seismic stratigraphy. den transition dips to the NW defining a thickness which varies between 2 and $4 \mathrm{~m}$; the reflector shows a good agreement with the boundary behaviour estimated from the VES. In the electric stratigraphy along line 4 the depth of the contact between the resistive sublayer and the conductive overburden was located at about $3 \mathrm{~m}$.

The map of the total magnetic anomaly (fig. 12) is more difficult to interpret because the values show a rather tight range. Nevertheless it is possible to recognize a high just in the centre of the doline.

\section{Case 2: the Turbiglie Basin (Roburent - Cuneo)}

The third doline investigated is known as the Turbiglie Basin (fig. 13) located SE of Roburent (Cuneo) in Northwestern Italy (fig. 1). The karst area of Roburent overlies the MesoTriassic limestone formations which are part of the Ligurian Brianzonese Zone. In particular,

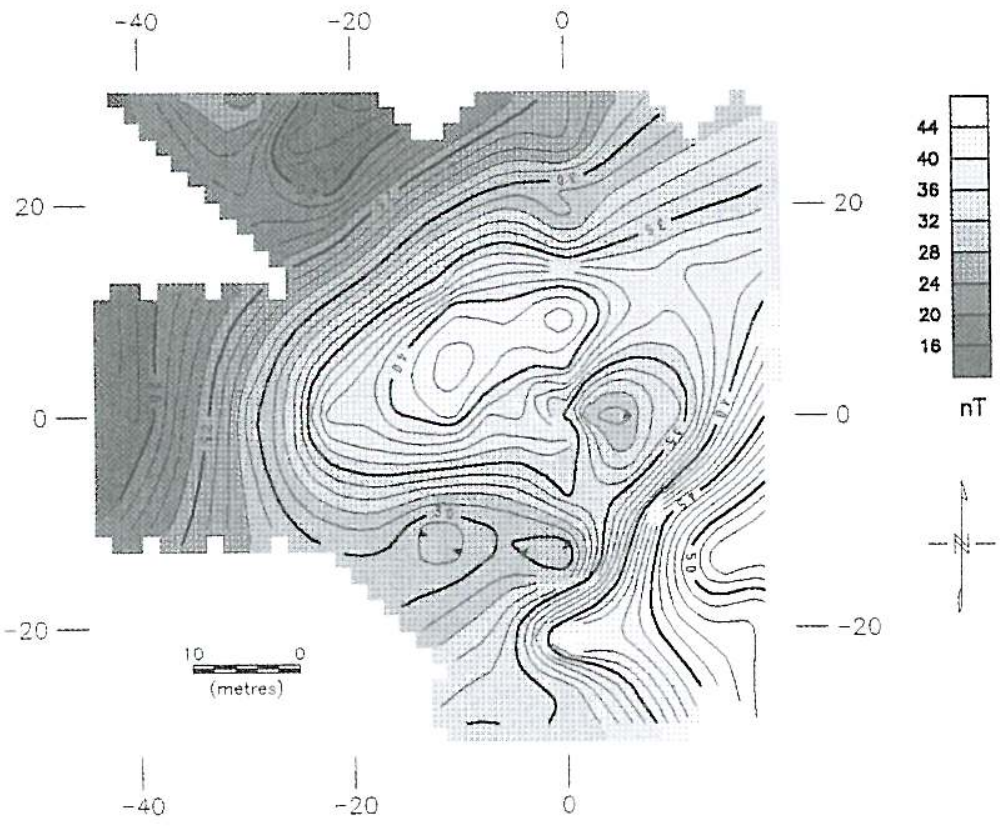

Fig. 12. Bric Tana site. Doline 2: map of the total magnetic anomaly field $\Delta F(\mathrm{nT})$. 


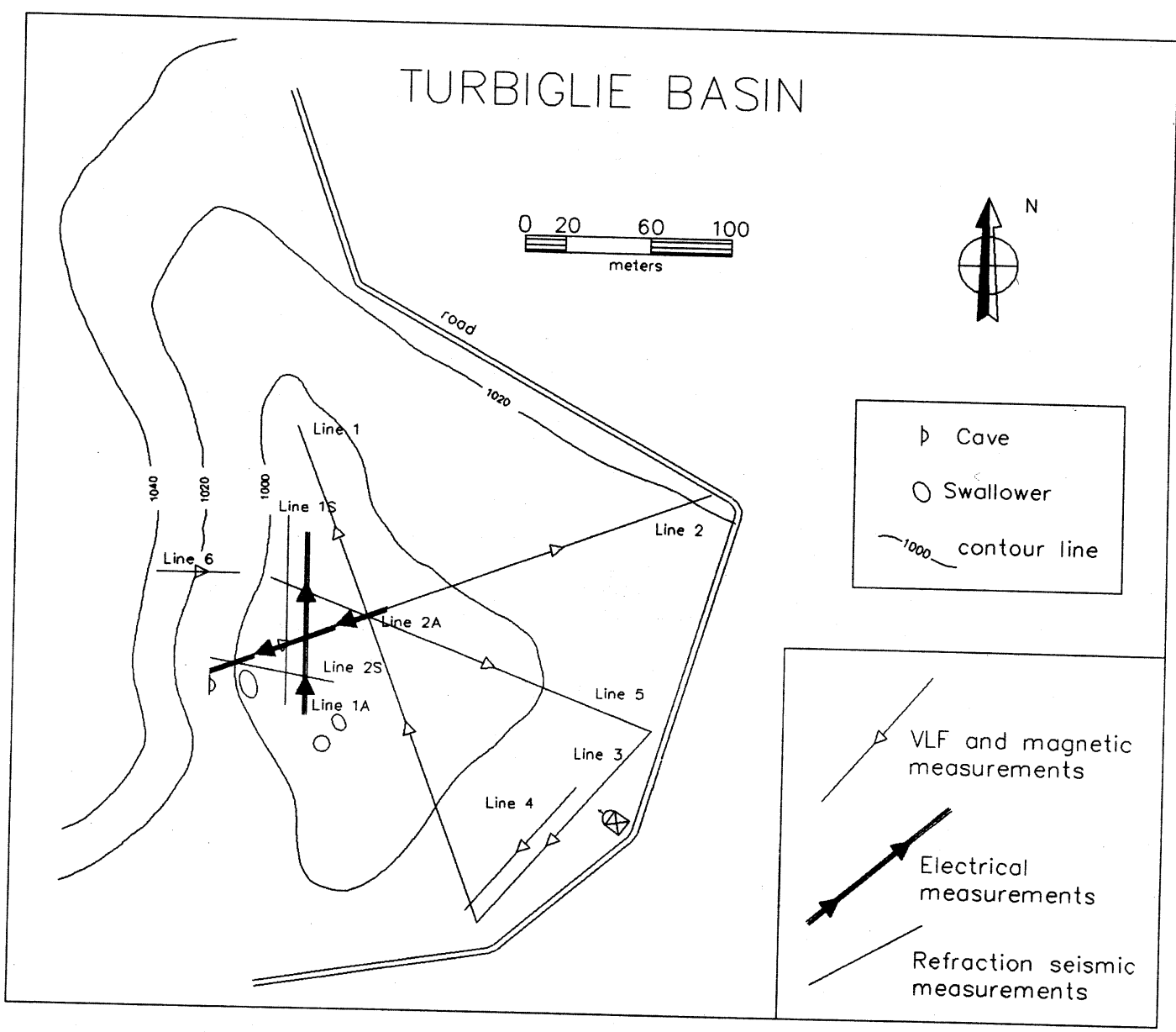

Fig. 13. Turbiglie Basin site. Schematic plan of the investigated area and position of the survey lines.

the Turbiglie Basin occurs at the contact between the Meso-Triassic limestone formations to the $\mathrm{W}$ and the impermeable terrains of the Permocarboniferous integument (Cerro et al., 1975; Vigna, 1982) underneath them and outcropping along the road cut which follows the eastern margin of the doline.

The lithological contact has strongly influenced both the shape of the doline (with a maximum elongation of about $300 \mathrm{~m}$ parallel to the contact) and the action of the groundwater. The slope composed of impermeable rocks (in the eastern part) channels water and debris towards the slope composed of limestone, where erosion is concentrated. Evidence for such action is represented by the strong steepness of the limestone slope, which is often affected by collapse and shows an abrupt contact with the bottom of the doline. The map of the in-phase VLF component (fig. 14) clearly shows how the contour lines closely follow the outline of the doline. As already observed in the previous cases the conductivity contrast is due to the thickness and/or conductivity variation of the infill. Therefore the area of maximum values of the in-phase VLF component occurs near the eastern side of the doline and is elongate parallel to the lithological contact. 


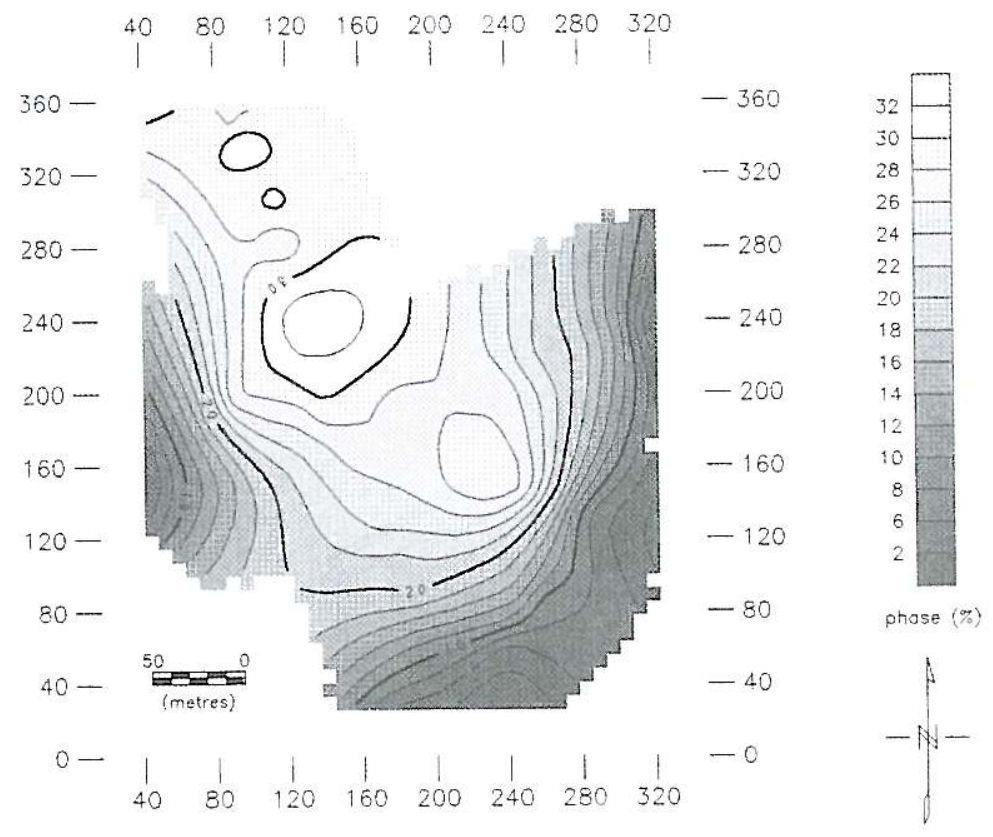

Fig. 14. Turbiglie Basin site. Map of the VLF (\%) in phase component.

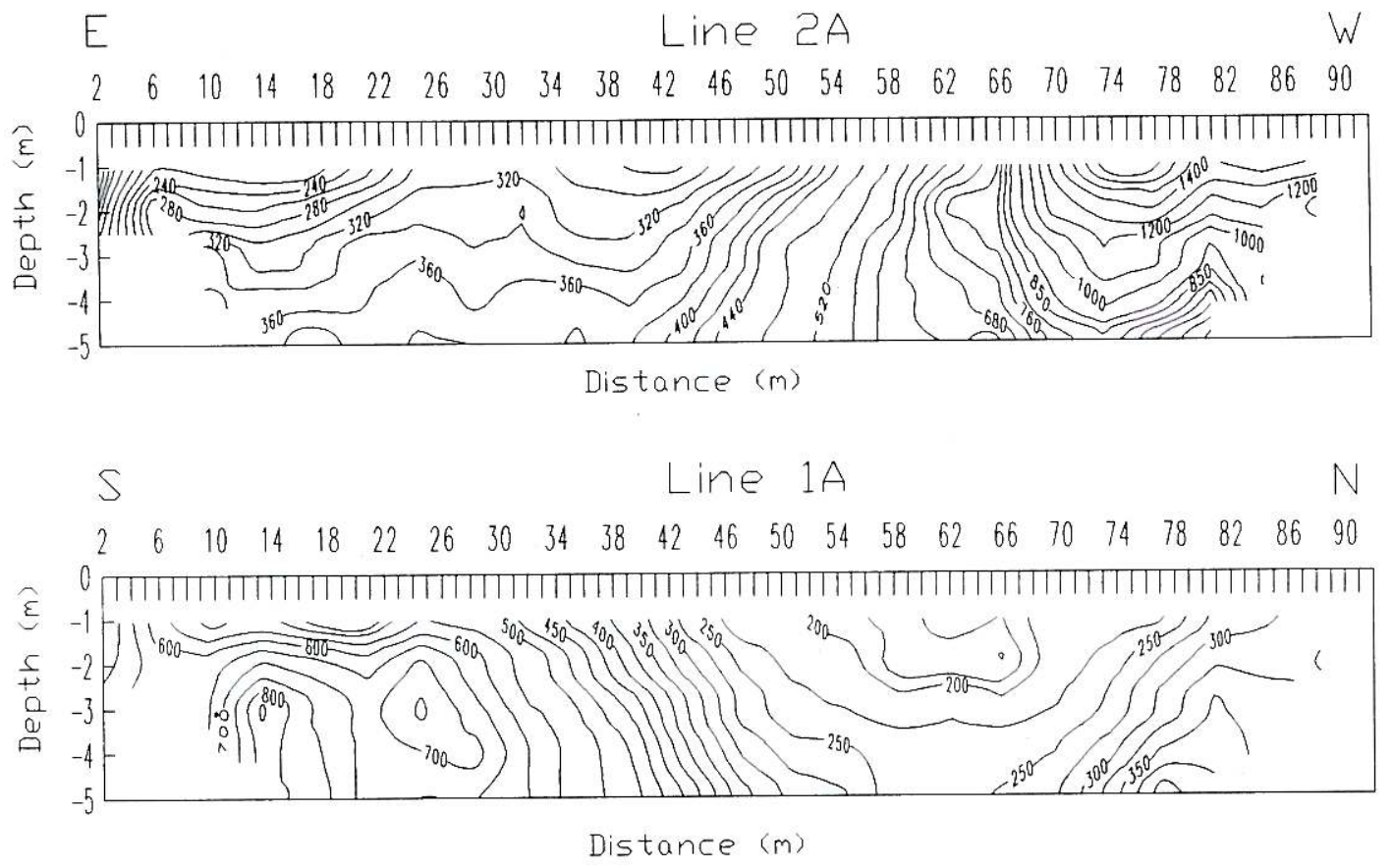

Fig. 15. Turbiglie Basin site. Pseudosections of apparent resistivity along lines $1 \mathrm{~A}, 2 \mathrm{~A}$ of fig. 13 . 
The pseudosections of apparent resistivity (fig. 15) related to the two lines of measurement, perpendicular to each other, at the bottom of the doline do not provide deep indications, and the shape of the contour lines do not show good details of the morphology of the transitional horizon between overburden and sublayer. An estimate of the depth of the sublayer is given by models of the electric stratigraphy derived from the VES along line $1 \mathrm{~A}$. The transition between the resistive sublayer and the conductive overburden is estimated at a depth of about $9 \mathrm{~m}$.

Along the same direction a refraction seismic profile was carried out. The model derived from the seismic stratigraphy (fig. 16a,b) shows that the transition between sublayer and infill, corresponding to the second refractive horizon, dips to the $N$ and is located at depths ranging from 12 to $18 \mathrm{~m}$. The difference between the depths calculated by VES and seismic refraction can be interpreted as due to the presence of a consistent weathered top of the bedrock.
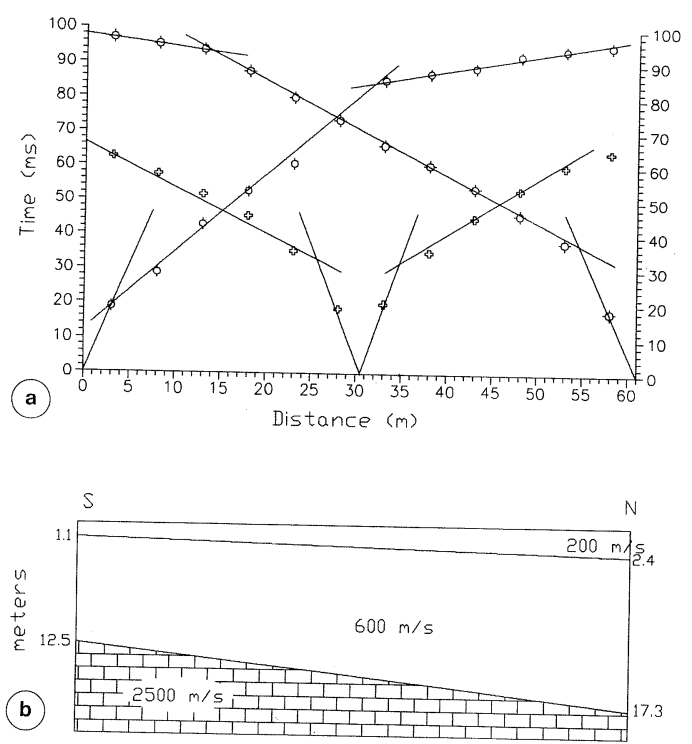

Fig. 16a,b. Turbiglie Basin site. Seismic refraction profile along $1 \mathrm{~S}$ line of fig. 13. a) Dromocrones; b) seismic stratigraphy.
The anomaly magnetic field proved to be very flat; it can be due to the very low contrast in magnetic susceptibility between materials forming the sublayer and the infill.

In general, the geological-structural setting of the doline characterized not only by the lithological contact but also by faults perpendicular to its maximum elongation cannot be accurately defined through the geophysical investigations carried out.

\section{Case 3: the Caves - Manie Plateau (Savona)}

The top surface of the Manie Plateau (Savona) in Western Liguria (fig. 1) is characterized by a series of hills separated by karst valleys with a flat bottom filled with Mediterranean Red Beds. The doline occurs to the south of the village of Voze and is located at the head of one of the karst valleys which belongs to the Cockpit of the Landrazza (Biancotti et al., 1991). The tendency of this karst valley to evolve in a regressive sense has led to the gradual destruction of the valley-side of the doline through the removal of its lower part.

The bottom of the doline (fig. 17) is filled with Red Beds deposits, whereas the steep slopes which form its boundaries are composed of the Meso-Triassic dolostones of the Formation of San Pietro dei Monti. In the same figure the location of the lines of the geophysical survey are shown. From the VLF profiles of lines 4, 5 and 6 of the survey (fig. 18), a substantial difference from the same type of measurements taken on the other dolines can be observed. The relative values of the intensity of the in-phase component are higher than those of the in-quadrature component, and the phase/ quadrature ratio varies substantially along the entire line; at the northeastern end of the doline it reaches its lowest value.

The map of the in-phase VLF component (fig. 19) suggests a subdivision in NE-SW trending bands. The VLF parameters are substantially influenced by the structural setting of the sublayer characterized by the occurrence of sub-vertical surfaces of discontinuity and having N-S and E-W strike directions. These sur- 


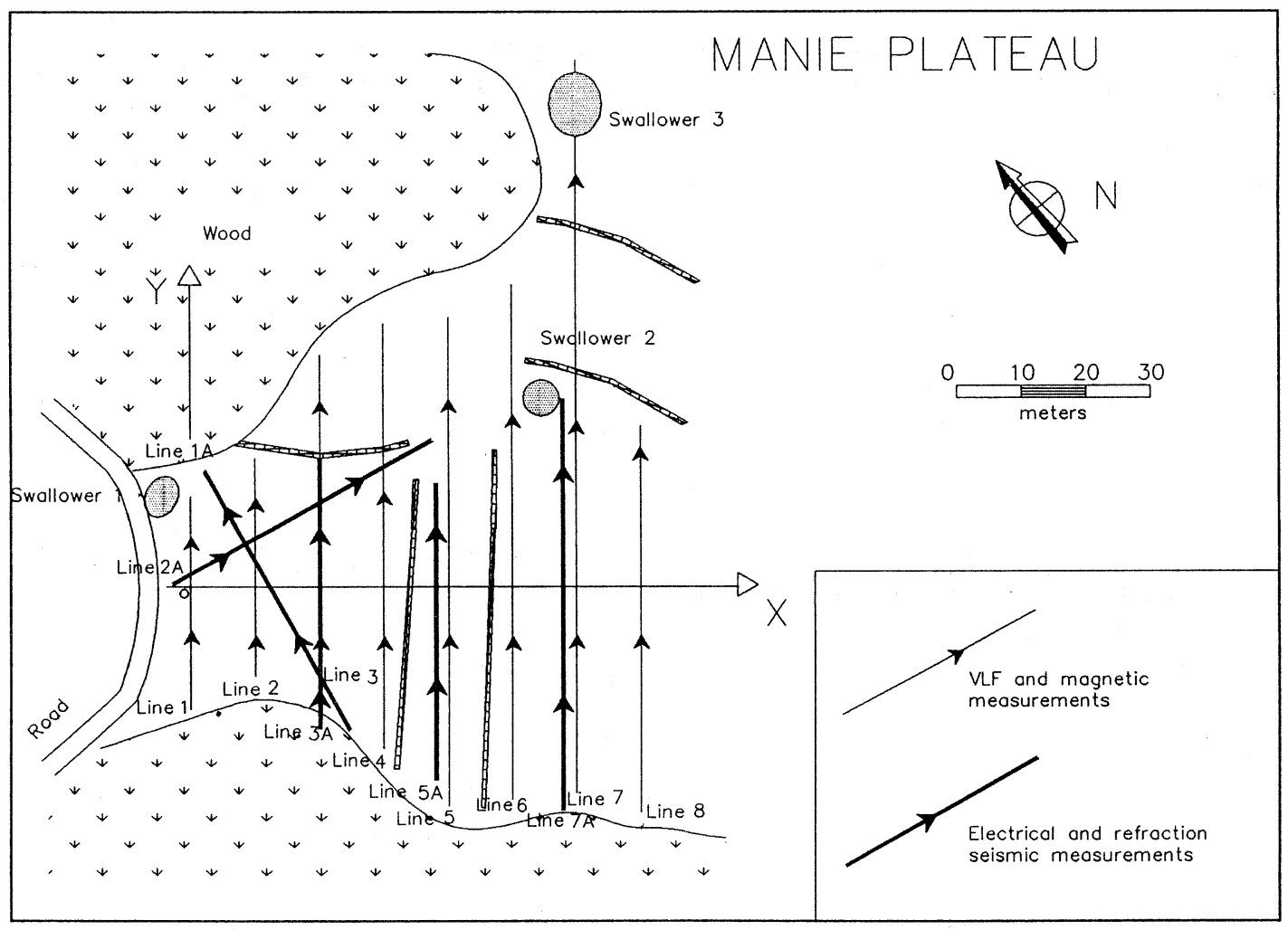

Fig. 17. The Caves site. Manie Plateau: schematic plan of the investigated area and position of the survey lines.

faces can be interpreted as tectonic elements which provided constraints on the initial evolution of the doline.

The $\Delta F$ total magnetic map (fig. 20) shows a high positive magnetic anomaly with an E-W elongation, and another, less intense, with N-S elongation. Since the measured magnetic susceptibility $\left(K_{m}\right)$ contrast between the infill composed of Red Beds and the dolostone forming the sublayer is equal to two orders of magnitude $\left(K_{m}=60 \times 10^{-6} S I\right.$ for the dolostone against $K_{m}=1130 \times 10^{-6} S I$ for the Red Beds), a correlation between intensity of these anomalies and the thickness of the infill can be proposed. Therefore, the magnetic map shows an effective representation of the distribution of the infill on the bottom of the doline, which shows the maximum thickness in accordance with the positive anomaly extending along the E-W direction.

An estimate of the maximum thickness of the infill was derived from a Schlumberger resistivity survey along this direction. The electric stratigraphy derived from this survey shows that the sublayer-infill transition occurs at a depth of about $5 \mathrm{~m}$. The seismic stratigraphy suggests the presence of a refractor dipping toward $\mathrm{E}$ at depths between 6 and $9 \mathrm{~m}$. Indicative is also the bedrock seismic velocity, which reached about $3500 \mathrm{~m} / \mathrm{s}$.

The dipolar pseudosection of apparent resistivity (fig. 21) seems to indicate that the sublayer is affected by fracture planes and inhomogeneous distribution of the infill. 

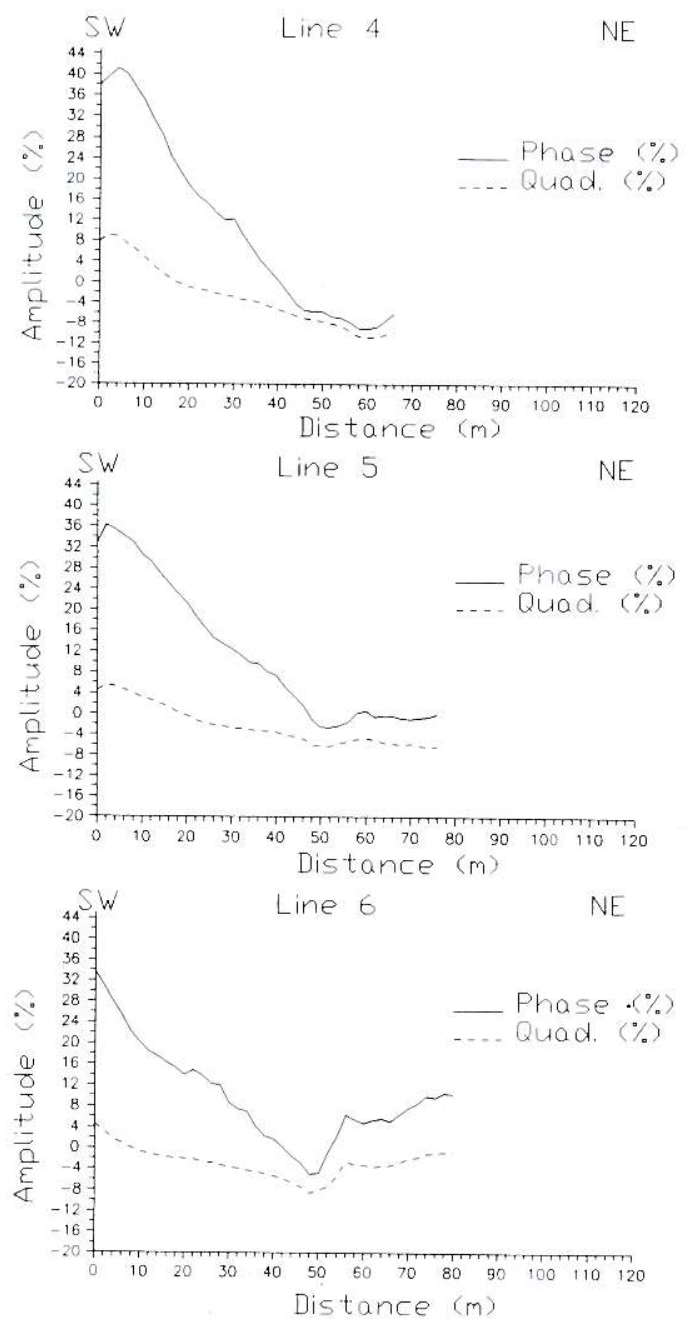

Fig. 18. The Caves site. Manie Plateau: VLF profiles for the survey lines $4,5,6$ of fig. 17.

It is clear from these results that the geological strike of this doline corresponding to the $\mathrm{N}-\mathrm{S}$ and $\mathrm{E}-\mathrm{W}$ directions is very different from its morphological equivalent with a valley axis characterized by an approximate SE-NW direction. Therefore the previously proposed hypothesis is confirmed postulating that the evolution of the doline took place in two separate stages: during the first, typically karstic, the

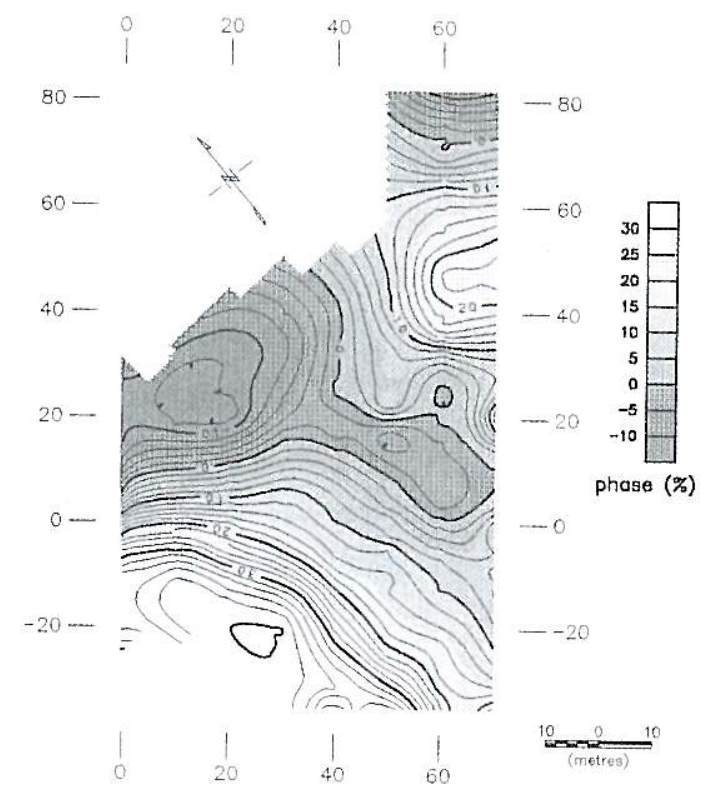

Fig. 19. The Caves site. Manie Plateau: map of the VLF (\%) in phase component.

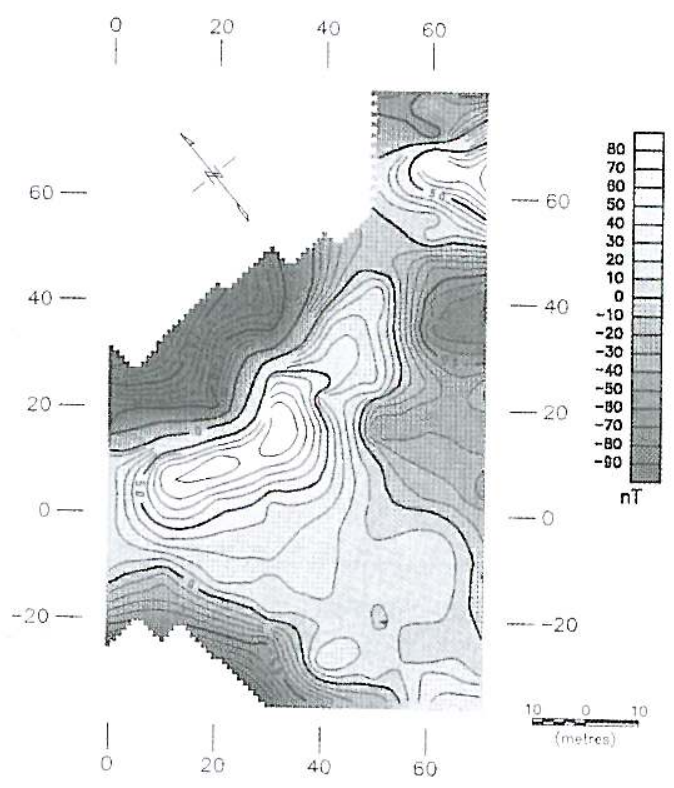

Fig. 20. The Caves site. Manie Plateat map of the total magnetic anomaly field $\Delta F$ (nT). 

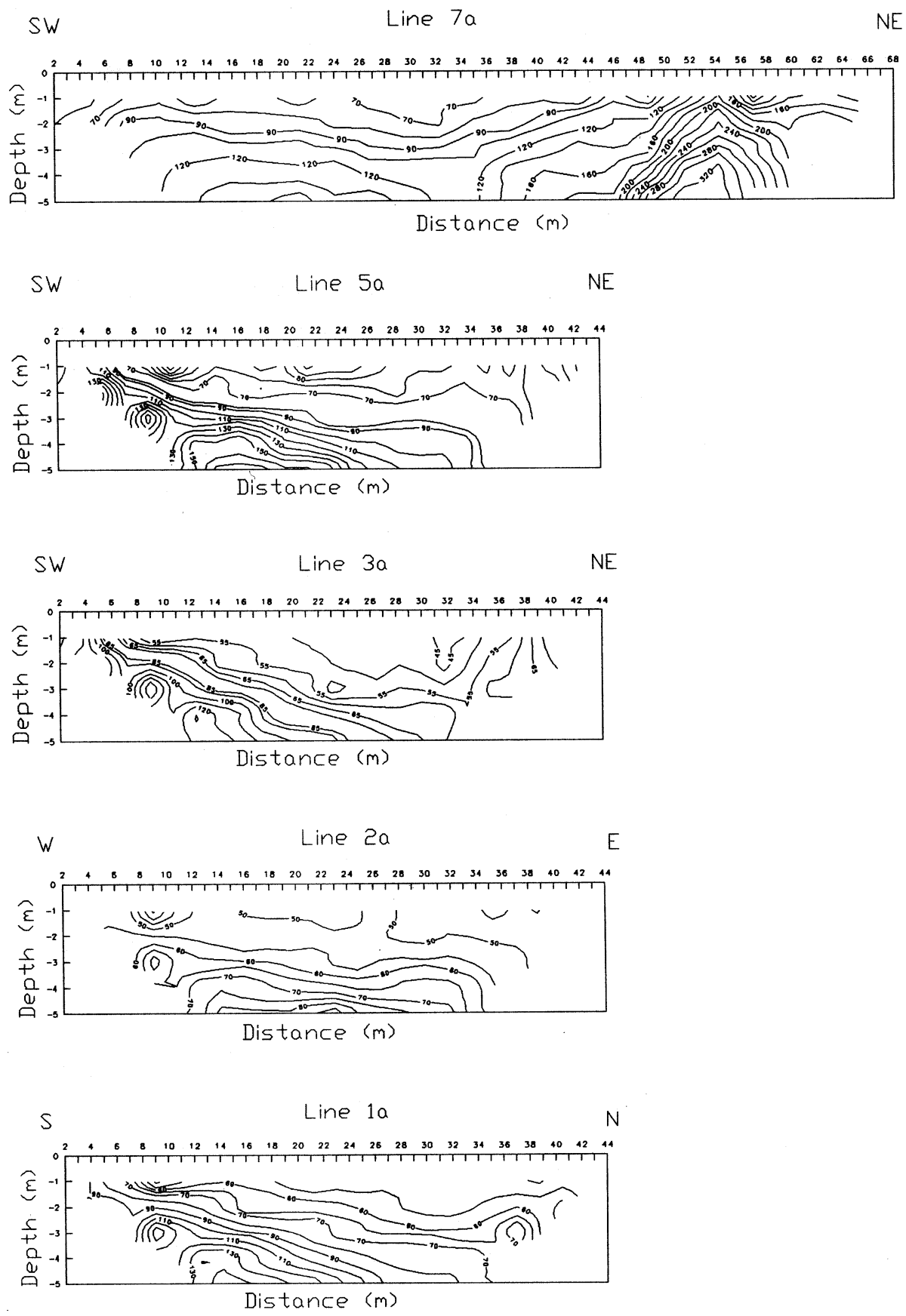

Fig. 21. The Caves site. Manie Plateau: pseudosections of apparent resistivity along lines $2 \mathrm{~A}, 3 \mathrm{~A}, 5 \mathrm{~A}$ and $7 \mathrm{~A}$ of fig. 17. 
doline evolved, as an independent entity, at the intersection between two weak tectonic elements; during the second a fluviatile-karstic evolution occurred because of the interception and the destruction carried out by one of the karstic valleys of the Cockpit.

\section{Conclusions}

In all the cases examined, the integrated analysis of the geophysical data defined the most important characteristics of the dolines, as, for example, the geological-structural setting on which the karst structures occur, their evolutionary trends, the geometrical (thickness) and geophysical (electrical, magnetic and seismic) properties of the materials forming the infill. In spite of the dolines under investigation having been found to be very different from each other by type and origin, the results obtained through different methods show common features which offer a comprehensive evaluation of their characteristics of resolution and convenience.

A first evaluation relates to the VLF method, which is generally used to detect conductivity contrasts on subvertical layers; in this case it was employed in a situation of subhorizontal stratigraphy. Even under these conditions this method provided more than satisfactory results showing a sensitivity to the lateral conductivity contrast controlled by thickness and/or homogeneity of the overburden.

The magnetic method yielded important results where the magnetic properties contrast between the sublayer and the infill allowed measurement of positive anomalies comparable to those detected through the analysis of the VLF data in relation to the larger thickness of the overburden.

In any case the geoelectric method produced the best resolution in defining the morphology of the contact between the sublayer and the overburden (through profiles) and the thicknesses relevant to the investigation (through electrical soundings).

The refraction seismic method showed some problems because of the too schematic model employed for data acquisition. It would have been more appropriate to use more shot points and, taking into account the shallow depths involved in the survey, more accurate evaluation of time arrivals. Alternatively, the application of the shallow depth reflection seismic method could be attempted.

Also the gravity method can be appropriate for detecting and characterizing karst features, but the data acquisition is much slower, the corrections and processing more exacting than the other methods such as magnetics and electromagnetics. However, as the density of the fill material approaches the density of the inplace rock, the gravity anomaly tends to zero. Therefore gravity is best used for karst structures which are air-filled and provide a maximum density contrast (Yuhr et al., 1993).

In conclusion, the site characterization to detect and map such subsurface features using geophysical techniques is adequate when it is based upon an understanding of project objectives and a conceptual geologic model of site conditions. The accuracy and effectiveness of using geophysics is heavily dependent upon: the identification of the suitable surface geophysical methods, the assessment of their spatial sampling, the sensitivities necessary to define those structures, and the capability of an adequate interpretation of the geophysical surveys to address borings which can provide a feedback of the identified geophysical anomalies.

\section{REFERENCES}

Biancotti, A., G. Brancucci and M. Motta (1991): Note illustrative della carta geomorfologica dell'Altopiano delle Manie e dei bacini idrografici limitrofi (Liguria Occidentale), Studi e Ricerche di Geografia, 14 (2), 155-177.

Bozzo, E., S. Lombardo and F. Merlanti (1994): VLF prospecting: observations about field experiments, Atti del IV Workshop di Geo-Elettro-Magnetismo, Capri 1992, Annali di Geofisica, 37 (6), 81-93.

Castiglioni, G.B. (1986): Geomorfologia (UTET, Torino), pp. 436.

Cerro, A., M. Oxilia and M. VAnossi (1975): Rapporti tra Brianzonese interno e Piemontese nella zona compresa tra le Valli del Casotto e del Pesio (Alpi Marittime), in Atti dell'Istituto di Geologia dell'Università di Pavia, 25, 72-78. 
Cortemiglia, G., E. ANDri and P. MAifredi (1968): Segnalazione di forme carsiche nella zona di Millesimo (Liguria Occidentale), Rassegna Speleologica Italiana, 20 (2), V, 67-84.

Milanovic, P.T. (1981): Karst Hydrogeology (Water Resources Publications, Colorado, U.S.A.), pp. 434.

Vigna, B. (1982): I sistemi carsici delle Alpi Liguri, in Atti del Convegno Internazionale sul Carso di Alta Montagna, Imperia, IV/V, 1982, 2 (1986), 166-177.
Yuhr, L., R. Benson and D. Butler (1993): Characterization of karst features using electromagnetics and microgravimetry: a strategic approach, in Proceedings of the Symposium on the Application of Geophysics to Engineering and Environmental Problems (SAGEEP '93), edited by R.S. BELL and C.M. LEPPER (Environmental and Engineering Geophysical Society, Englewood, CO, U.S.A.), 209-228. 